\title{
THE PROBLEM OF THE BANKRUPTCY CONCEPT DEFINITION IN THE CORPORATE SECTOR
}

\author{
Neli Muntean*, ORCID ID:0000-0001-6385-2890, \\ Iulian Muntean, Gabriela Valuța \\ Technical University of Moldova, 168 Stefan cel Mare Blvd., Chisinau, Republic of Moldova \\ *Corresponding author: Neli Muntean, neli.muntean@adm.utm.md
}

Received: 07. 24. 2021

Accepted: 08. 27. 2021

\begin{abstract}
The issue of the bankruptcy notion definition has a major importance in the context of the management practice and theory, internal planning and control of the company. The objectives of the article are to analyse the theoretical principles, highlight and systematize the most successful meanings and definitions related to the term of "bankruptcy", interpreting the economic content of such a category as "bankruptcy in the corporate sector". For this purpose, the method of analysis of the scientific literature was applied. The publications chosen as the research base were mainly selected from the Google Scholar and ResearchGate databases between 2016 and 2020. This study is one of the few researches that involves the analysis of the legal framework especially in the countries of the former Eastern bloc. The results show that the terms that are often used in the bankruptcy literature are: failure, insolvency and bankruptcy. These terms are sometimes used interchangeably, although formally each of them can be defined in a different way. At the same time, following the lexicographical analysis of the concept of bankruptcy in the sustainable development of a company, the authors proposed to visualize the correlation between bankruptcy, financial stability and sustainable development in the corporate sector.
\end{abstract}

Key words: bankruptcy, failure, insolvency, sustainable development, risk.

Rezumat. Problema definirii conceptului de faliment are o importanță semnificativă în domeniul teoretic și aplicativ al managementului, al planificării interne și controlului în sectorul corporativ. Obiectivul articolului constă în analiza și sistematizarea mai multor definiții aferente noțiunii de „faliment” și în interpretarea conținutului economic al unei asemenea categorii ca „falimentul în sectorul corporativ”. În acest scop, a fost aplicată metoda de analiză a literaturii științifice. Lucrările alese ca bază de cercetare au fost selectate din bazele de date Google Scholar și ResearchGate în perioada 2016 - 2020, studiul respectiv fiind unul din puținele cercetări cu referire la analiza legislației țărilor din fostul bloc estic. Rezultatele arată că termenii: eșecul, insolvența și falimentul, care sunt adesea utilizați în literatura de specialitate cu privire la faliment, sunt uneori utilizați în mod interschimbabil, deși formal fiecare dintre aceștia poate fi definit într-un mod diferit. Totodată, ca urmare a analizei lexicografice a conceptului de faliment în cadrul dezvoltării sustenabile a unei 
companii, autorii au propus spre vizualizare modul de corelare între faliment, stabilitatea financiară și dezvoltarea sustenabilă în sectorul corporativ.

Cuvinte cheie: faliment, eșec, insolvență, dezvoltare sustenabilă, risc.

\section{Introducere}

Luând în considerare transformările majore ce au avut loc în ultimele decenii sub incidența unei mișcări semnificative de liberalizare, inovare tehnologică și globalizare în economia națională, reducerea numărului de falimente în sectorul corporativ reprezintă astăzi una din noile provocări ale acestuia cu care se confruntă economiile contemporane, motiv pentru care dorim să efectuăm un studiu științific amplu asupra unei reașezări a conținutului, teoriilor și accepțiunilor privind conceptul de faliment în sectorul corporativ, pentru a-l adapta necesităților în schimbare ale mediului de afaceri.

În special problema falimentului devine una stringentă pe timp de pandemie COVID 19, când un număr enorm de companii, practic pe întreg globul au fost nevoite să-și sisteze activitățile [1].

La data de 24 iulie 2020 Agenția Servicii Publice din Republica Moldova în MO nr.188192 (7516 - 7520) a publicat avizul prin care aduce la cunoștință lista persoanelor juridice radiate din oficiu din Registrul de stat al persoanelor juridice a căror activitate a fost suspendată. Lista publicată conține denumirile a 968 de societăți comerciale, SRL și întreprinzători individuali. Radierea este efectuată în baza prevederilor art. $26^{1}$ din Legea nr. 220 - XVI privind înregistrarea de stat a persoanelor juridice și a întreprinzătorilor individuali.

Astfel, este relevant să fie analizată problematica conceptului de faliment.

Obiectivele și scopul articolului constau în analiza principiilor teoretice, evidențierea și sistematizarea celor mai reușite accepțiuni şi definiții aferente noțiunii de „faliment”, interpretarea conținutului economic al unei asemenea categorii ca „falimentul în sectorul corporativ". Din acest motiv, această cercetare încearcă să răspundă la următoarele întrebări: 1) Cum este definit conceptul de faliment? 2) În ce constă analiza lexicografică a conceptului de faliment, stabilității financiare și a dezvoltării sustenabile în sectorul corporativ?

În acest scop, a fost aplicată metoda de analiză a literaturii științifice. Publicațiile alese ca bază de cercetare, în principal, au fost selectate din bazele de date Google Scholar și ResearchGate în perioada 2016 - 2020. Acest studiu este unul din puținele cercetări ce implică analiza literaturii științifice și a legislației în special în țările din fostul bloc estic. Rezultatele arată că termenii care sunt adesea utilizați în literatura de specialitate cu privire la faliment sunt: eșecul, insolvența și falimentul. Acești termeni sunt uneori utilizați în mod interschimbabil, deși formal fiecare dintre aceștia poate fi definit într-un mod diferit. Totodată, autorii au analizat conceptul de faliment în cadrul dezvoltării sustenabile a unei companii, presupunând că dezvoltarea sustenabilă a unei companii reprezintă o funcție compusă din mai multe elemente (precum cele de mediu, economice, sociale, și structurale), una dintre care fiind stabilitatea financiară.

\section{Recenzia literaturii științifice}

Cercetările în domeniul falimentului unei entități sunt relevante deoarece au drept sop eficientizarea procedurilor de insolvență și restructurare. În țările dezvoltate, primele cercetări aferente determinării gradului de faliment au avut loc la începutul secolului '20. Prima cercetare a fost inițiată în Statele Unite. Inițial, cercetătorii au utilizat indicatori unici sau rate financiare pentru a face diferența între entitățile insolvabile și cele solvabile. Beaver 
(1966) a fost primul economist care a utilizat metode statistice pentru predicția riscului de faliment al întreprinderilor [2]. În 1968, Altman a creat unul dintre cele mai cunoscute și, de asemenea, primul model de predicție a falimentului, cunoscut sub numele de „scor Z” [3]. Din acel moment, numărul modelelor de faliment a crescut. În anii 1970, au fost publicate peste 28 de studii despre modelele de predicție; în anii 1980 au fost publicate peste 53 de studii; iar în anii 1990 au fost publicate peste 70 de studii. Astfel, Cândido Peres și Mario Antão, în anul 2018, [4] au putut identifica 123 de modele diferite de predicție a riscului de faliment. Conform analizei lor, cele mai cercetate țări din acest domeniu sau cele cu cel mai mare număr de modele publicate sunt Statele Unite (30), Marea Britanie (21) și Spania (16) cu aproximativ 24\%, $17 \%$ și $13 \%$ din total, respectiv.

În ceea ce privește țările Europei Centrale și de Est, studiul acestui subiect de cercetare datează cu începutul anilor 1990. Anume în această perioadă au avut loc primele cazuri de faliment. În prima perioadă, în majoritatea țărilor Europei Centrale și de Est, din cauza lipsei bazelor de date statistice, pentru a determina nivelul riscului de faliment, au fost folosite modelele de predicție preluate de la țările dezvoltate. Apoi au fost efectuate analize, studii mai complicate, la baza cărora erau cercetările savanților din țările dezvoltate și au fost elaborate modele naționale de prezicere a riscului de faliment [5].

A. Miff și M. Costin, menționează că etimologia noțiunii „faliment” arată că aceasta a provenit din limba latină, de la cuvântul „fallo-fallere”, tradus prin a scăpa, a lipsi - sensul fiind că falitul nu-şi efectuează obligația de a achita creditorilor săi, dar reprezentând concomitent și sensul în latină de a înșela [6, p. 7].

Cuvântul a fost împrumutat în limba italiană sub noțiunea de fallere, în sensul de a greși, a înceta o plată și denumirea „falimento” (în germană - falliment) [7, p. 365], care se traduce prin faliment, eroare, greșeală şi chiar înșelăciune. Comerciantul în incapacitate de a achita a fost numit falito în limba italiană, noțiune preluată în limba română sub denumirea de falit (om insolvabil; persoană care se află în stare de faliment; care se află într-o situație dezastruoasă, care a suferit un eșec total [7, p. 365]), în limba franceză poartă denumirea de failli, în limba spaniolă - fallido, iar în engleză - fallure şi bunkrupty. Terminologia are însă aceeași semnificație: falimentul presupune o instituție juridică ce reglementează modul de executare silită a activelor debitorului comerciant aflat în stare de incapacitate a plăților. Astfel, de obicei, starea de fapt în care se află comerciantul care a încetat să-și achite datoriile comerciale se numește faliment. Prin aceeași noțiune este denumită starea juridică a comerciantului împotriva căruia a fost pronunțată o sentință declarativă de faliment.

Astfel, analiza problematicii falimentului nu reprezintă un element novator pentru știința economică, totuși în ultima perioadă tot mai mulți specialiști îi acordă o atenție deosebită.

\section{Metodologia cercetării}

Această lucrare încearcă să răspundă la următoarele întrebări: 1) Cum este definit conceptul de faliment? 2) În ce constă analiza lexicografică a conceptului de faliment, stabilității financiare și a dezvoltării sustenabile în sectorul corporativ? În acest scop, a fost aplicată metoda de analiză a literaturii științifice. Mai mult decât atât, pe parcursul studiului a fost aplicată metoda universală a dialecticii şi procedeele acesteia: deducția și inducția, sinteza și analiza, analogia, corelarea, abstracția științifică, cât și cele ale analizei economice de prelucrare a informației: sistematizarea, compararea, etc. Concomitent au fost folosite așa 
metode ca: analiza comparativ-critică asupra literaturii, documentarea, analiza documentară, metode statistice de analiza, abordarea constructivista, abordarea pozitivistă.

Baza teoretică şi metodologică de cercetare a prezentei lucrări o constituie lucrările fundamentale ale savanților din S.U.A., statele C.S.I., Europa, şi din alte ţări, actele normative şi legislative ale Republicii Moldova, Rusia, Ucraina, Armenia, Letonia, Estonia, etc. Publicațiile alese ca bază de cercetare, în principal, au fost selectate din bazele de date Google Scholar și ResearchGate în perioada 2016 - 2020.

\section{Rezultate și discuții}

Obiectivele și scopul articolului constau în analiza principiilor teoretice, evidențierea și sistematizarea celor mai reușite accepțiuni și definiții aferente noțiunii de „faliment”, interpretarea conținutului economic al unei asemenea categorii ca „falimentul în sectorul corporativ". Unii dintre termenii care sunt adesea utilizați în literatura de specialitate cu privire la faliment sunt: eșecul, insolvența și falimentul. Acești termeni sunt uneori utilizați în mod interschimbabil, deși formal fiecare dintre aceștia poate fi definit într-un mod diferit, de ex. eșecul poate fi definit ca incapacitatea unei afaceri de a continua, în special din cauza lipsei de bani, insolvența indică faptul că activele nete ale firmei au valoare negativă, sau/și neîndeplinirea unui lucru cerut (de exemplu, neîndeplinirea unui contract, cum ar fi plata datoriilor cuiva), iar falimentul se referă la declarația oficială de faliment a unei firme. În continuare vom încerca să analizăm mai detaliat acești trei termeni.

Insolvabilitatea este tratată sub două aspecte: în sens larg falimentul denotă o instituție juridică, un ansamblu de norme juridice ce reglementează relațiile aferente urmăririi activelor debitorului insolvabil, indiferent de faptul daca acesta e supus lichidării sau își recuperează capacitatea de plată. În sens restrâns, prin insolvabilitate înțelegem o totalitate de norme juridice, care stipulează că activele debitorului sunt expuse vânzării, numerarul se împarte între creditori, iar debitorul insolvabil, persoana fizica, este lipsit de statutul de întreprinzător, iar cel, persoana juridica, se lichidează.

Drept urmare a unei analize a actelor legislative ale 9 țări, autorii au ajuns la concluzia că criteriile financiare generale pentru inițierea procesului de insolvabilitate a unei companii sunt:

- incapacitatea de plată (incapacitatea de a-și achita obligațiile la timp);

- supra îndatorarea (excesul de datorie asupra activelor companiei).

Principalele diferențe dintre temeiurile de insolvabilitate, stabilite în actele legislative din aceste nouă țări, se referă la valoarea și termenul de neplată a datoriilor (a se vedea tabelul 1).

Tabelul 1

Criterii generale pentru fundamentarea procedurilor de insolvență

\begin{tabular}{cll}
\hline \multicolumn{1}{c}{ Țara } & \multicolumn{1}{c}{ Criteriul 1 } & \multicolumn{1}{c}{ Criteriul 2 } \\
\hline Letonia [8, 9] & $\begin{array}{l}\text { Datorie }>\text { 4268 euro; termen }-3 \\
\text { săptămâni după notificarea neplății } \\
\text { datoriei }\end{array}$ & pierderi $\geqslant$ 1/2 capital social \\
\hline Lituania [10] & $\begin{array}{l}\text { suma nu este specificată; 30 de zile după } \\
\text { notificare }\end{array}$ & $\begin{array}{l}\text { Datoriile }>1 / 2 \text { din valoarea } \\
\text { activului }\end{array}$ \\
\hline Estonia [11] & $\begin{array}{l}\text { suma nu este specificată; 1 lună după } \\
\text { data scadenței + 10 zile după notificare }\end{array}$ & Datoriile > active \\
\hline
\end{tabular}


Continuare Tabelul 1

\begin{tabular}{lll}
\hline Armenia [12] & $\begin{array}{l}\text { datorii> } 1000 \text { salarii minime; termen - 60 } \\
\text { de zile de la data întârzierii }\end{array}$ & $\begin{array}{l}\text { Datoriile }>\text { active }(>1000 \\
\text { salarii minime) }\end{array}$ \\
\hline Ucraina [13, 14] & $\begin{array}{l}\text { datorii> } 300 \text { salarii minime; } 3 \text { luni după } \\
\text { data scadenței }\end{array}$ & Datoriile > active \\
\hline Bielorusia [15] & îndatorare 100 unități convenționale & Datoriile > active \\
\hline Rusia [16] & $\begin{array}{l}\text { suma nu este specificată; } 3 \text { luni după } \\
\text { data scadenței }\end{array}$ & Datoriile > active \\
\hline Kazahstan [17] & $\begin{array}{l}\text { datorii } 300 \text { indici lunari de calcul; } 3 \text { luni } \\
\text { de la data întârzierii }\end{array}$ & Datoriile > active \\
\hline Moldova [18] & $\begin{array}{l}\text { suma nu este specificată; } 15 \text { zile după } \\
\text { notificare }\end{array}$ & Datoriile > active \\
\hline
\end{tabular}

Sursa: Elaborat de autori în baza actelor normative ale țărilor analizate.

Totodată, pentru a identifica insolvența marilor companii, reglementările multor țări sugerează utilizarea metodei „activelor nete”, care este direct identificată cu conceptul de capital propriu al companiei, deși esența economică a acestei abordări este mult mai largă. Conform prevederilor Standardului internațional de contabilitate (IAS) nr.321: "Activele nete ale unei organizații sunt acele active care rămân după deducerea tuturor creanțelor aferente activelor sale."[19] Aplicarea metodei „activelor nete” este prezentă implicit în Legea comercială a Republicii Letonia, în legislația fiscală a Republicii Armenia [20]. Procedura de calcul a „activelor nete” este definită în reglementările Federației Ruse [21] și ale Republicii Belarus [22]. În Republica Moldova această reglementare se regăsește în Legea privind S.A. [23].

În ceea ce privește, eșecul economic al unei entități, acesta este condiționat de mai multe cauze, și anume:

1. incompetență şi greșeli de conducere (60\%);

2. evoluția nefavorabilă a pieței (circa 20\%);

3. incendii, fenomene naturale, cutremure, calamități, inundații (10\%);

4. alți factori (10\%).

Putem remarca că factorul semnificativ îl reprezintă greșelile în procesele de management şi de analiză a pieței. Falimentul are loc atunci când un debitor este incapabil să îndeplinească la timp obligațiile de plată către debitori sau se poate prezice această incapacitate de îndeplinire.

Atunci, creditorii au obligația de a decide dacă vor dizolva firma prin procedura de lichidare, sau o vor păstra, optând pentru o reorganizare. Decizia respectivă se bazează pe compararea valorii companiei în condițiile în care este realizată, cu valoarea activelor sale, dacă acestea sunt vândute separat.

Diferența între faliment şi eșec este că falimentul este un proces care începe financiar şi se termină legal, în vreme ce eșecul nu are neapărat o componentă juridică.

Momentul precis în care apare falimentul este dificil de precizat. El apare în urma unor decizii subiective din perioada în care firma are probleme financiare. Creditorii sunt adesea cei care decid acțiunea legală de lichidare. Eșecul financiar e necesar, dar nu suficient ca condiție a falimentului. 
Astfel, drept urmare a analizei mai multor accepțiuni cu privire la faliment, insolvabilitate și eșec în tabelul 2 autorii au rezumat definițiile utilizate în unele studii. Majoritatea studiilor folosesc o definiție pur legislativă a falimentului.

Tabelul 2

Accepțiuni privind conceptul de faliment

\begin{tabular}{|c|c|}
\hline $\begin{array}{l}\text { Dreptul } \\
\text { roman }(200- \\
1600)[6]\end{array}$ & $\begin{array}{l}\text { Falimentul reprezenta o procedură prin care o societate înceta, } \\
\text { confiscându-i-se sau vânzându-i-se bunurile, iar comercianții falimentari } \\
\text { erau considerați infractori, fiind deseori vânduți sau chiar omorâți pentru } \\
\text { neonorarea obligațiilor sale. }\end{array}$ \\
\hline $\begin{array}{l}\text { Dicționarul } \\
\text { economic și } \\
\text { financiar [24] }\end{array}$ & $\begin{array}{l}\text { Falimentul presupune "situația economică în dificultate a unui debitor, } \\
\text { aflat în incapacitatea de a-şi onora obligațiunile comerciale (față de } \\
\text { creditori); stare de insolvabilitate a debitorului stabilită de către tribunal } \\
\text { având ca bază declarația falitului ori cererea unuia sau a mai multor } \\
\text { creditori. }\end{array}$ \\
\hline $\begin{array}{l}\text { Beaver (1966) } \\
{[2]}\end{array}$ & $\begin{array}{l}\text { Falimentul poate fi definit ca fiind incapacitatea unei firme de a-și plăti } \\
\text { obligațiile financiare pe măsură ce acestea se maturizează. } \\
\text { Din punct de vedere operațional, se spune că o firmă a falimentat atunci } \\
\text { când au avut loc oricare dintre următoarele evenimente: insolvabilitate, } \\
\text { neplată de obligațiuni, un cont bancar depășit sau neplata unui dividend } \\
\text { pe acțiuni preferat. }\end{array}$ \\
\hline $\begin{array}{l}\text { Altman } \\
(1968)[3]\end{array}$ & $\begin{array}{l}\text { Falimentul este definit ca acele firme care sunt în stare de faliment legal } \\
\text { și care sunt plasate în creanță sau au primit dreptul de a se reorganiza în } \\
\text { conformitate cu prevederile Legii naționale a falimentului. }\end{array}$ \\
\hline $\begin{array}{l}\text { Ohlson (1980) } \\
{[25]}\end{array}$ & $\begin{array}{l}\text { Definiția firmelor eșuate este pur legalistă. Firmele care au eșuat trebuie } \\
\text { să fi depus pentru faliment sau a unei alte notificări care indică procedura } \\
\text { de faliment }\end{array}$ \\
\hline $\begin{array}{l}\text { Shumway } \\
(2001)[26]\end{array}$ & $\begin{array}{l}\text { Definiția falimentului: firmele care au depus orice tip de faliment sunt } \\
\text { considerate falimentare. }\end{array}$ \\
\hline $\begin{array}{l}\text { Legea } \\
\text { insolvabilității } \\
\text { nr.149 [18] }\end{array}$ & $\begin{array}{l}\text { Procedură a falimentului - procedură de insolvabilitate concursuală } \\
\text { colectivă și egalitară care se aplică debitorului în vederea lichidării } \\
\text { patrimoniului acestuia pentru acoperirea pasivului. }\end{array}$ \\
\hline
\end{tabular}

Sursa: Elaborat de autori.

După părerea autorilor, definirea noțiunii de faliment este una diferită de la an la an și de la stat la stat. Realitatea obiectivă ne spune ca falimentul presupune starea în care entitatea nu are capacitatea de a-și onora datoriile. De aici realitatea juridică vine să concretizeze că trebuie să existe o hotărâre de judecată prin care să demonstrezi ca nu ai mijloace suficiente și cu această decizie poți alege una din doua căi: reorganizarea sau lichidarea firmei.

Falimentul este în general o procedură ce afectează tot patrimoniul, și ce este caracteristic acestei proceduri este că toate drepturile debitorului sunt pierdute, astfel administratorul își pierde toate drepturile asupra bunurilor sale, care ulterior vor fi vândute pentru acoperirea datoriilor sale.

Mai mult, studiul terminologiei privind conceptul de faliment în sectorul corporativ nu poate fi efectuat fără o cercetare amănunțită a corelației dintre termenii de faliment și cel de stabilitate financiară și dezvoltare sustenabilă. 
Astfel, autorii au analizat termenul de faliment în cadrul dezvoltării sustenabile a unei companii, specificând că dezvoltarea sustenabilă a unei companii reprezintă o funcție a mai multor elemente (precum cele sociale, de mediu, structurale și economice), una din care este stabilitatea financiară.

Totodată, analiza lexicografică a termenului de faliment în contextul unei dezvoltări sustenabile în sectorul corporativ, a presupus studiul următorilor termeni: solvabilitate, stabilitate financiară; dezvoltare sustenabilă; echilibru; creștere, etc. Rezultatele studiului lexicografic a accepțiunilor sunt reprezentate în figura 1. Modul de corelare între faliment, stabilitatea financiară și dezvoltarea sustenabilă în sectorul corporativ propus de autori poate fi vizualizat mai jos:

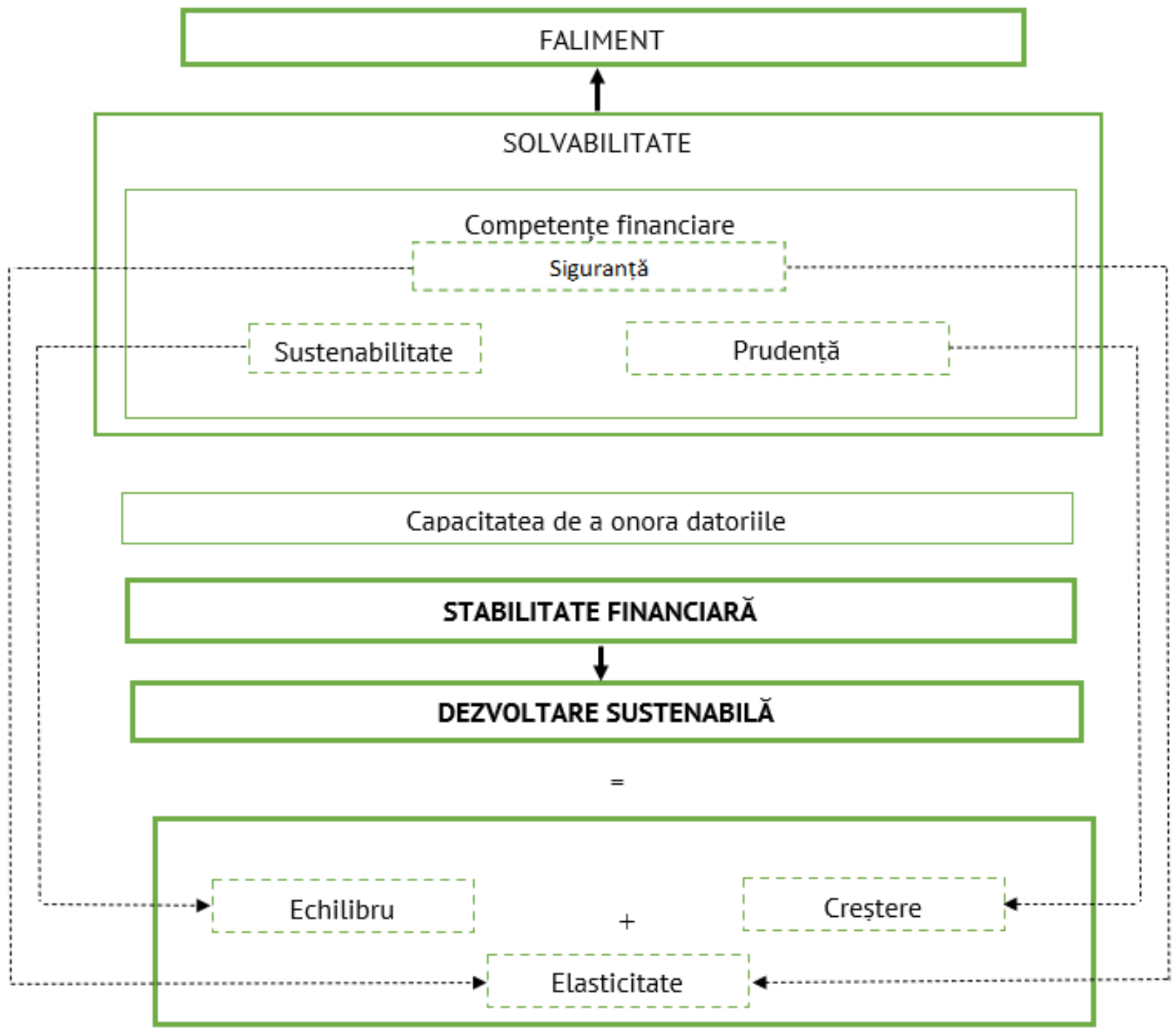

Figura 1. Analiza lexicografică a termenului de faliment în sectorul corporativ. Sursa: adaptat de autori în baza surselor 27 și 28.

\section{Concluzii}

Analiza lexicografică și definirea termenului de faliment face posibilă determinarea corelației funcționale între conceptele studiate:

1) "Stabilitatea financiară" este o condiție de realizare a "dezvoltării sustenabile". "Creșterea", "echilibrul" și "elasticitatea" specifică gradul stabilității financiare. 
2) "Echilibrul, "creșterea" și "elasticitatea" face posibilă "stabilitatea". "Prudența" semnifică temelia unei "creșteri", "sustenabilitatea" însă este baza unui "echilibru". lar «siguranța» semnifică «elasticitate».

3) "Competența financiară" reprezintă rezultatul iminent al "siguranței", "prudenței" și "sustenabilității".

4) Solvabilitatea unei entități presupune "capacitatea de a onora obligațiunile " cu un accent vădit asupra "competenței financiare" a companiei, și anume pe: capacitatea de a lua decizii curajoase, riscante, orientate spre rezultat, pentru a fi competitiv noilor provocări. Mai mult, "falimentul", conform prevederilor legislației Republicii Moldova, reprezintă o hotărâre judecătorească irevocabilă în cadrul procedurilor judiciare privind "insolvabilitatea".

Ca urmare a studiilor și analizelor efectuate, putem conchide că procedura de faliment este o procedură de insolvență concursuală, colectivă şi egalitară, care se aplică debitorului cu scopul lichidării bunurilor acestuia în vederea acoperirii pasivului, fiind continuată de radierea debitorului din oficiu din Registrul de stat al persoanelor juridice a căror activitate a fost suspendată. Falimentul în sectorul corporativ presupune firmele aflate în dificultate financiară, firmele inactive, firmele care au fost lichidate obligatoriu și firmele care au înregistrat o supra îndatorare sau o vânzare forțată.

\section{Referințe}

1. Vladimir Plotnikov, luliia Ugarov, and Evgeniia Ugarova. The impact of economic crises on the Russian cheese market. E3S Web Conf. Volume 175, 2020. XIII International Scientific and Practical Conference "State and Prospects for the Development of Agribusiness - INTERAGROMASH 2020". Disponibil: https://doi.org/10.1051/e3sconf/202017513045

2. Beaver W. Financial Ratios as Predictors of Bankruptcy. Journal of Accounting Research, vol. 6, pp. 71-102, 1966.

3. Altman E. I. Financial Ratios, Discriminant Analysis and the Prediction of Corporate Bankruptcy. Journal of Finance, vol. 23, no. 4, pp. 589 - 609, 1968.

4. Peres C., Antão M. The use of multivariate discriminant analysis to predict corporate bankruptcy: A review AESTIMATIO. The IEB International Journal of Finance, 14, pp. 108 - 131. 2017. Disponibil: https://www.researchgate.net/publication/310003046.

5. Bła zej Prusak. Review of Research into Enterprise Bankruptcy Prediction in Selected Central and Eastern European Countries. Int. J. Financial Stud. 2018, 6, 60. Disponibil: doi:10.3390/ijfs6030060.

6. Costin M., Miff A. Falimentul. Evoluţie şi actualitate. Bucureşti: Lumina Lex, 2000, 383 p.

7. Furdui V. Falimentul - concept şi reglementări actuale. Institutul pentru Dezvoltare şi iniţiative Sociale „Viitorul”. Chişinău: tiSh, 2004.

8. Maksatnespejas likums: Latvijas Republikas likums no 26.07.2010. Saeima, 2010 (ar izmainam uz 19.06.2019).

9. Komerclikums: Latvijas Republikas likums no 13.04.2000. Saeima, 2000 (ar izmainam uz 19.06.2019).

10. Imoniu bankroto istatymo: Lietuvos Respulbikos istatymo 20.03.2001., №. IX-216. Seimas, 2001.

11. Pankrotiseadus: Eesti Vabariigi seadus 22.01.2003. Riigikogu, 2003 (19.03.2019).

12. O neplatezhespobnosti (bankrotstve): Zakon Respubliki Armeniya от 22.01.2007, № 3P-51.

13. Metodychni rekomendatsii shchodo vyiavlennia oznak neplatospromozhnosti pidpryiemstva i oznak dii z prykhovuvannia bankrutstva, fiktyvnoho bankrutstva abo dovedennia do bankrutstva: nakaz Ministerstva ekonomiky Ukrainy vid 19.01.2006, № 14 (stanom na 26.10.2010).

14. Pro vidnovlennia platospromozhnosti borzhnyka abo vyznannia yoho bankrutom: Zakon ot 14.05.1992, № 2343Khll (iz zminamy stanom na 04.04.2018).

15. Ob ekonomicheskoy nesostoyatelnosti (bankrotstve): Zakon Respubliki Belarus ot 13.07.2012, № 415-3. Prinyat Palatoy predstaviteley. 2012 (s izmeneniyami na 15.11.2016).

16.O nesostoyatelnosti (bankrotstve): Federalnyy zakon Rossiyskoy Federatsii ot 26.10.2002, № 127-FZ. Prinyat Gosudarstvennoy Dumoy. 2002 (s izmeneniyami na 29.05.2019).

17. 0 reabilitatsii i bankrotstve: Zakon Respubliki Kazakhstan ot 07.03.2014, № 176-V (s izmeneniyami na 02.04.2019). 
18. Legea insolvabilităţii nr. 149 din 29.06.2012. Publicat : 14-09-2012 în Monitorul Oficial Nr. 193-197 art. 663. 19. Financial instruments: presentation: ISA standardat 1991, September, № 32. IFAC, 1991 (reissued at 2003).

20. Nalogovyy kodeks Respubliki Armeniya: Zakon Respubliki Armeniya ot 04.10.2016 (v redaktsii ot 04.10.2016).

21. Ob utverzhdenii Poryadka opredeleniya stoimosti chistykh aktivov: prikaz Minfina Rossii ot 28.08.2014, № 84- $N$ (s izmeneniyami na 21.02.2018).

22.0 Poryadke rascheta stoimosti chistykh aktivov: Postanovleniye Ministerstva finansov Respubliki Belarus ot 11.06.2012, № 35 ( $v$ redaktsii ot 11.06.2012).

23. LEGE Nr. 1134 din 02-04-1997 privind societăţile pe acţiuni. Publicat : 12-06-1997 în Monitorul Oficial Nr. 3839 art. 332.

24.Dicţionar explicativ al limbii române. Ediţia a II-a. Conducătorul lucrării: I. Coteanu. Bucureşti: Univers enciclopedic, 1998, $1192 \mathrm{p}$.

25. Ohlson J. A. Financial Ratios and the Probabilistic Prediction of Bankruptcy. Journal of Accounting Research, vol. 19, pp. 109 - 131. 1980.

26. Shumway T. Forecasting Bankruptcy More Accurately: A Simple Hazard Model. Journal of Business, vol. 74, no. 1, 2001. pp. 101 - 124

27. Muntean N. Analiza stabilității financiare în sectorul corporativ: Monografie; Chișinău: Cartier, 152 p. 2019. ISBN 978-9975-86-407-7.

28. Muntean N. Accepţiuni ale conceptului de stabilitate financiară în sectorul corporativ. In: Competitivitate şi inovare în economia cunoaşterii [online]: conf. șt. intern., ed. a 21-a: Lucrări ştiinţifice, 27 - 28 sept., 2019. Chişinău: ASEM, 2019, pp. 515 - 522. ISBN 978-9975-75-968-7. 